\section{Toxoplasma gondii and pre-treatment protocols for polymerase chain reaction analysis of milk samples: a field trial in sheep from Southern Italy}

\author{
Alice Vismarra, ${ }^{1}$ Elena Barilli, ${ }^{2}$ \\ Maura Miceli, ${ }^{2}$ Carlo Mangia, ${ }^{2}$ \\ Cristina Bacci, ${ }^{2}$ Franco Brindani, ${ }^{2}$ \\ Laura Kramer ${ }^{2}$ \\ ${ }^{1}$ Institute for Experimental Veterinary \\ Medicine of Brescia, Brescia; \\ ${ }^{2}$ Department of Veterinary Sciences, \\ University of Parma, Parma, Italy
}

\begin{abstract}
Toxoplasmosis is a zoonotic disease caused by the protozoan Toxoplasma gondii. Ingestion of raw milk has been suggested as a risk for transmission to humans. Here the authors evaluated pre-treatment protocols for DNA extraction on $T$. gondii tachyzoite-spiked sheep milk with the aim of identifying the method that resulted in the most rapid and reliable polymerase chain reaction (PCR) positivity. This protocol was then used to analyse milk samples from sheep of three different farms in Southern Italy, including real time PCR for DNA quantification and PCR-restriction fragment length polymorphism for genotyping. The pre-treatment protocol using ethylenediaminetetraacetic acid and Tris- $\mathrm{HCl}$ to remove casein gave the best results in the least amount of time compared to the others on spiked milk samples. One sample of 21 collected from sheep farms was positive on one-step PCR, real time PCR and resulted in a Type I genotype at one locus (SAG3). Milk usually contains a low number of tachyzoites and this could be a limiting factor for molecular identification. Our preliminary data has evaluated a rapid, cost-effective and sensitive protocol to treat milk before DNA extraction. The results of the present study also confirm the possibility of T. gondii transmission through consumption of raw milk and its unpasteurised derivatives.
\end{abstract}

\section{Introduction}

Toxoplasmosis is a zoonotic disease caused by the protozoan Toxoplasma gondii. The infection is widespread in humans and several mammals species, such as sheep, pigs, goats and cattle (Hill and Dubey, 2013; EFSA, 2016; Vismarra et al., 2016). In immunocompetent humans, the infection is usually asymptomatic but vertical transmission can lead to the risk of stillbirth, abortion or severe cerebral problems, as hydrocephalus (Havelaar et al., 2007; Hampton, 2015). In sheep, T. gondii is an important cause of abortion, which can result in considerable economic losses (Buxton et al., 2007).

The main routes of $T$. gondii transmission are congenital and through consumption of contaminated food and water. Transmission by food may occur with the ingestion of sporulated oocysts present in vegetables or water and/or tissue cysts present in raw or undercooked meat. The transmission of $T$. gondii with raw milk has been reported and several studies demonstrated the presence of the parasite's DNA in sheep milk (Bezerra et al., 2015; de Santana Rocha et al., 2015; Luptakova et al., 2015). In Italy, the consumption of sheep milk (397.510 ton in 2015) is second only to the consumption of cow milk (11.161.224 ton in 2015) (www.istat.it). Moreover, almost all dairy products derived from sheep milk are prepared with unpasteurised milk. Different studies showed the presence of $T$. gondii DNA in raw milk using different protocols of polymerase chain reaction (PCR). The problem of extracting DNA from milk is related to the presence of fat that interferes with most of the commonly used reagents; sheep milk in particular is characterised by high percentage of fat $(6.9 \%)$ (Mancianti et al., 2013; Da Silva et al., 2015).

The aim of this study was to evaluate different pre-treatment protocols to reduce interference with DNA extraction from milk, in order to evaluate the most reliable method. Three protocols described in literature have been selected and tested to identify the best one in terms of sensitivity, simplicity in performing and time necessary to analyse samples. Moreover, we performed a real-time PCR to evaluate the presence of $T$. gondii DNA in sheep milk collected from farms. Positive samples were genotyped with a multiplex multilocus nested PCRrestriction fragment length polymorphism (RFLP).

\section{Materials and Methods}

\section{Protocol set up with milk spiked with Toxoplasma gondii tachyzoites}

Fresh, unpasteurised sheep milk spiked with $T$. gondii tachyzoites was used to evaluate pre-treatment protocols. Tachyzoites of
Correspondence: Cristina Bacci, Department of Veterinary Sciences, University of Parma, via del Taglio 10, 43126 Parma, Italy.

Tel: +39.0521.032740.

E-mail: cristina.bacci@unipr.it

Key words: Toxoplasma gondii; Serology; Meat juice; ELISA.

Conflict of interest: the authors declare no potential conflict of interest.

Acknowledgements: the authors would like to thank sheep farmers for their cooperation in samples collection.

Received for publication: 20 December 2016. Revision received: 24 January 2017.

Accepted for publication: 24 January 2017.

This work is licensed under a Creative Commons Attribution-NonCommercial 4.0 International License (CC BY-NC 4.0).

(C) Copyright A. Vismarra et al., 2017

Licensee PAGEPress, Italy

Italian Journal of Food Safety 2017; 6:6501

doi:10.4081/ijfs.2017.6501

T. gondii RH strain were obtained from infected Vero cells and enumerated to prepare parasites for milk contamination. Six $10 \mathrm{~mL}$-aliquots of milk were spiked with either $10^{5}$ or $10^{6}$ tachyzoites. Table 1 summarises the protocols used in the spiked milk samples. For all the protocols applied, samples were first incubated overnight at $+4^{\circ} \mathrm{C}$ and the superficial fat layer was removed the next day.

Protocol I was described by Qiagen company and did not foresee any pre-treatment except a series of centrifugations. It is perfectly adptable to the DNA extraction kit commonly used in our laboratory (DNeasy Blood \& Tissue kit, Qiagen). Milk samples were homogenised at $37^{\circ} \mathrm{C}$ for $15 \mathrm{~min}$, vortexed and centrifuged at $6000 \mathrm{xg}$ for 10 min. Supernatant was removed and the cell pellet resuspended with $7.5 \mathrm{~mL}$ of PBS. A second centrifugation was done and the resulting pellet was resuspended with $1 \mathrm{~mL}$ of PBS. Samples were then vortexed and centrifuged again for $10 \mathrm{~min}$. Finally the cell pellet was resuspended with $200 \mu \mathrm{L}$ of PBS.

Protocol II was described by Mancianti et al. (2013) and applied to remove caseins that could interfere with DNA extraction. Briefly, T. gondii-spiked samples were centrifuged at $2200 \mathrm{xg}$ for $5 \mathrm{~min}$. Pellets were resuspended with $200 \mu \mathrm{L}$ of TE buffer and $300 \mu \mathrm{L}$ of EDTA $0.5 \mathrm{M}$, then centrifuged again at $3000 \mathrm{xg}$ for $10 \mathrm{~min}$. The supernatant was removed and $200 \mu \mathrm{L}$ PBS were 
added to the pellet.

Protocol III was described by Da Silva et al. (2015). Briefly, $300 \mu \mathrm{L}$ of spiked milk were added to $900 \mu \mathrm{L}$ of Lysis solution (Buffer AL; Qiagen, Hilden, Germany) and $20 \mu \mathrm{L}$ of proteinase $\mathrm{K}$ (Qiagen) and incubated at $56^{\circ} \mathrm{C}$ overnight.

All samples from the three protocols were then subjected to DNA extraction using a commercial kit (DNeasy Blood \& Tissue Kit; Qiagen) and T. gondii PCR, as described below.

Three samples of non-spiked milk were used as negative controls.

\section{Analysis of milk samples collected from naturally exposed sheep}

In March 2016, 21 sheep milk samples were collected from three different farms (A, B, C) located in the Apulia region of southern Italy. Teats were cleaned and disinfected, the first three to four milk jets were discarded, and approximately $100 \mathrm{~mL}$ of milk were collected from each animal. Samples were maintained at $4^{\circ} \mathrm{C}$ until use. They were then pooled into four batches (Table 2) and analysed as described below. Furthermore, six single milk samples were analysed from Farm A due to reports of recent abortion in these animals.

Based on results from testing of spiked sheep milk, samples were pre-treated with protocol II before DNA extraction.

\section{Real-time polymerase chain reaction}

DNA was extracted from all milk samples using a commercial kit (DNAeasy Blood and Tissue kit; Qiagen). The presence of $T$. gondii DNA was determined by PCR, targeting the Repeat Region 529 bp, using the primers TOX4 and TOX5, as described by Homan et al. (2000). Positive controls (DNA of $T$. gondii tachyzoites extracted from reference strains cultured in the laboratory) and negative controls were included in all reactions. The products were fractionated on $2 \%$ agarose gel, stained with SyBR $^{\circledR}$ Safe (Invitrogen, Carlsbad, CA, USA) and visualised by UV transilluminator. Sheep milk samples were also analysed with real-time PCR SYBR green assay (Edvinsson et al., 2006) targeting the Repeat Region 529 bp marker. The amplification protocol was characterised by a denaturation step $\left(95^{\circ} \mathrm{C}\right.$ for $\left.5 \mathrm{~min}\right)$ and 45 repeated cycles $\left(95^{\circ} \mathrm{C}-15 \mathrm{sec} ; 58.5^{\circ} \mathrm{C}-30\right.$ $\mathrm{sec})$. Fluorescence signals were collected in every cycle and the presence of aspecific products was avoided through melting curve analysis. To determine the copy number of the sequences a standard curve was made as follow. Samples of T. gondii DNA (extracted from tachyzoites) were amplified for the Repeat Region 529 bp marker and run on agarose gel. The PCR product was purified directly from the gel using a commercial kit (JETQUICK Gel Extraction Spin Kit; Genomed, Saint Louis, MO, Germany) and quantified through spectrophotometry (Eppendorf, Hamburg, Germany). The number of copy per ng of DNA was then calculated. The molecular weight of each copy was determined using the sequence registered in the NCBI database (accession number: AF146527) and a web tool (http://www.bioinformatics.org/). The standard curve was fitted within at least four points, with concentrations ranging between $1.6 \mu \mathrm{g}$ and $1.6 \mathrm{ng}$.

For each sample, at least four replicates were used and the average value of $\mathrm{Ct}$ and DNA quantity for each sample was used for statistical analysis.

\section{Toxoplasma gondii genotyping in naturally exposed sheep}

Sheep milk samples identified as positive in PCR were genotyped with a multiplex multilocus nested PCR-RFLP protocol, according to $\mathrm{Su}$ et al. (2010). Genetic markers namely SAG1, SAG2, SAG3, BTUB, GRA6, C22-8, C29-2, L358, PK1 and APICO were amplified. The PCR products were examined by electrophoresis in 1.5\% agarose gel and visualised under UV light. To reveal the RFLP pattern, PCR products were digested with specific endonucleases with single or double digestions mixed with $10 \mu \mathrm{L}$ of the digestion reaction containing specific buffer and restriction enzymes (Table 3). Each reaction was carried out by incubating at the proper temperature for each restriction enzyme following the manufacturer's instruction (ThermoFisher
Scientific, Waltham, MA, USA). The digested PCR products were resolved in a $2.5-3 \%$ agarose gel by electrophoresis and visualised by UV transilluminator. The genetic profile was defined comparing the samples with positive controls, one for each type, RH (Type I), ME49 (Type II), VEG (Type III).

\section{Results}

Results for PCR analysis carried out on spiked sheep milk samples contaminated with $T$. gondii tachyzoites and treated with three different protocols before the DNA extraction, were all positive, indicating no substantial differences in terms of sensitivity of the methods tested. None of the negative controls was positive.

In terms of the time necessary to obtain DNA, protocol I required at least one hour, protocol II approximately $20 \mathrm{~min}$ and protocol III over $24 \mathrm{~h}$. Protocol II was chosen for analysis of field samples.

About sheep milk collected on farms, none of the pools was positive for $T$. gondii DNA. However, only one (n. 5) out of the six single samples analysed, from Farm A revealed a good band on agarose gel after PCR, indicating the presence of $T$. gondii DNA in the milk. It was genotyped only at one locus, revealing a Type I profile for the SAG3 marker.

When evaluating pools and single samples with Real-Time PCR, however, it appeared that a low amount of DNA was present in all the samples, excluded sample

Table 1. Protocols for pre-treatment of Toxoplasma gondii-spiked milk samples.

\begin{tabular}{lccc} 
Aliquot (n) & $\begin{array}{c}\text { Contamination rate } \\
\text { (tachyzoites/10 mL) }\end{array}$ & Protocol & Tlime needed \\
\hline 1 & $10^{5}$ & I & $1 \mathrm{~h}$ \\
\hline 2 & $10^{6}$ & II & $20 \mathrm{~min}$ \\
\hline 3 & $10^{5}$ & & $24 \mathrm{~h}$ \\
\hline 5 & $10^{6}$ & III & \\
\hline 6 & $10^{5}$ & & \\
\hline
\end{tabular}

I, no pre-treatment; II, anti-casein treatment; III, overnight incubation at $56^{\circ} \mathrm{C}$.

Table 2. Sample collection and pooling for polymerase chain reaction identification of Toxoplasma gondii in milk samples from naturally exposed sheep.

\begin{tabular}{lccc} 
Sample collection and pooling & Farm A & Farm B & Farm C \\
Milk samples collected (n) & 10 & 6 & 5 \\
Pools (n) & 2 & 1 & 1 \\
\hline Samples examined for each pool (n) & 5 & 6 & 5
\end{tabular}


n. 4 that was negative

The lowest $\mathrm{Ct}$ value recorded was 31.52 and the total amount of DNA was calculated in the order of about $0.04 \mathrm{pg}$ and corresponding to $6.6 \times 10^{4}$ gene copies. The positive control (DNA sample extracted from milk contaminated with $10^{5}$ tachyzoites of $T$. gondii) had a mean Ct value of 19.7.

\section{Discussion}

One of the most important goals of the diagnostic tools in animal production is to improve methods aimed at avoiding the introduction of human pathogens into the food chain. Methods must be reliable, repeatable and, when possible, rapid. Here the authors report that the pre-treatment of T. gondii tachyzoite-spiked sheep milk samples with a protocol aimed at removing caseins before DNA extraction (Mancianti et al., 2013), was equally efficient when compared to other, more cumbersome and time-consuming methods. Indeed, there was no difference among the three protocols tested when samples were screened by parasite-specific PCR.

Studies on $T$. gondii-naturally infected animals are important because they report what has actually occurred in farms and they indicate what could be present in the human food chain (Bacci et al., 2016). In the present study, a preliminary survey on milk samples coming from sheep bred in southern Italy was carried out following method evaluation of spiked samples. One sample out of $21(4.7 \%)$ resulted positive by end-point PCR (n. 5) and genotyping confirmed a Type I allele for the genetic marker SAG3. This does not however imply that this, more pathogenic genotype is currently circulating, due to a lack of complete marker analysis.

Pool samples were negative, but when analysed with a Real-Time PCR they showed a positive signal, indicating the presence of $T$. gondii DNA, even though at a very low concentration. It would be necessary to obtain further information on farm management and age of ewes in order to better evaluate the true prevalence of positive milk.

The occurrence of tachyzoites in the milk of naturally infected ewes and goats has been reported by several authors as Camossi et al. (2011) and de Santana Rocha and colleagues (2015). A study conducted in Brazil reported that $6.5 \%$ of sheep milk samples were positive for $T$. gondii DNA (da Silva et al., 2015). Another interesting study on milk and blood samples for the presence of Toxoplasma DNA was performed by Fusco et al. (2007) in the Campania region (South of Italy). Milk and blood samples were collected from 117 Italian farms (1170 sheep). The PCR results confirmed $T$. gondii in four milk samples $(3.4 \%)$, demonstrating the transmission of the parasite through ovine milk and dairy products. Mancianti et al. (2013) detected DNA in 10 samples of milk and blood among 77 seropositive goats, indicating that $13 \%$ of seropositive goats were excreting $T$. gondii tachyzoites and thus DNA in their milk. As reported by Luptakova et al. (2015) tachyzoite excretion in milk is most likely during the acute phase of infection.

\section{Conclusions}

The results of the present survey confirm the possibility of Toxoplasma transmission through consumption of raw milk and its unpasteurised derivatives. Indeed, $T$. gondii contamination of milk should not be underestimated since it can represent a critical point in food safety. Some local homemade cheeses deriving from mass-milk production and destined to be consumed fresh can represent a risk factor for public health if they are produced in small family-based farms without previous milk pasteurisation. High quality DNA is essential for obtaining reliable results through PCR, qRT-PCR and PCR-RFLP. Milk contains a low number of tachyzoites and this could be a limiting factor for molecular identification. Our preliminary data has evaluated a rapid, cost-effective and sensitive protocol to treat milk before DNA extraction. Further studies are necessary, including a larger number of samples from more farms located in different geographical areas.

Table 3. Restriction enzymes (as described by Su et al., 2010) for the polymerase chain reaction-restriction fragment length polymorphism protocol.

\begin{tabular}{|c|c|c|c|c|}
\hline Genetic marker & Restriction enzymes & Temperature $\left({ }^{\circ} \mathrm{C}\right)$ & Buffer & Cutting site \\
\hline SAG1 & $\begin{array}{l}\text { Sau96I } \\
\text { HaeIII }\end{array}$ & $\begin{array}{l}37 \\
37\end{array}$ & $\begin{array}{l}\text { Tango } \\
\text { Tango }\end{array}$ & $\begin{array}{r}\text { 5' G } 1 \mathrm{GNCC} 3^{\prime} 3^{\prime} \mathrm{CCNG} \uparrow \mathrm{G} 5 \\
5^{\prime}-\mathrm{GG} \downarrow \mathrm{CC}-3^{\prime} 3^{\prime}-\mathrm{CC} \uparrow \mathrm{GG}-5^{\prime}\end{array}$ \\
\hline SAG2 & $\begin{array}{l}\text { Hinfl } \\
\text { TaqI }\end{array}$ & $\begin{array}{l}37 \\
65\end{array}$ & $\begin{array}{l}\text { Taq } \\
\text { Taq }\end{array}$ & $\begin{array}{c}\text { 5'G } \downarrow \text { ANTC3' 3'CTNA } \uparrow \text { G5' } \\
\text { 5'T } \downarrow \text { CGA3' 3'AGC } \uparrow T \text { T' }\end{array}$ \\
\hline SAG3 & Ncil & 37 & Tango & $5^{\prime} \mathrm{CC} \downarrow$ SGG 3' 3'GGS $\uparrow \mathrm{CC} 5^{\prime}$ \\
\hline GRA6 & MseI & 65 & $\mathrm{R}$ & 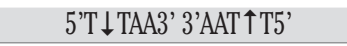 \\
\hline L358 & $\begin{array}{l}\text { HaelII } \\
\text { HinII }\end{array}$ & $\begin{array}{l}37 \\
37\end{array}$ & $\begin{array}{l}\mathrm{R} \\
\mathrm{R}\end{array}$ & 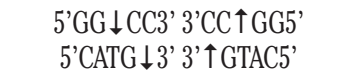 \\
\hline PK1 & $\begin{array}{l}\text { Rsal } \\
\text { Eco88I }\end{array}$ & $\begin{array}{l}37 \\
37\end{array}$ & $\begin{array}{l}\text { Tango } \\
\text { Tango }\end{array}$ & $\begin{array}{l}\text { 5'GT } \downarrow \text { AC3' 3'CA } \uparrow \text { TG5' } \\
\text { 5'ACGT } \downarrow \text { 3' 3'个TGCA5' }\end{array}$ \\
\hline C29-2 & $\begin{array}{l}\text { Rsal } \\
\text { MaeII }\end{array}$ & $\begin{array}{l}37 \\
65\end{array}$ & $\begin{array}{l}\text { Tango } \\
\text { Tango }\end{array}$ & $\begin{array}{l}\text { 5'GT } \downarrow \text { AC3' 3'CA } \uparrow \text { TG5' } \\
\text { 5'ACGT3' 3'TGCA5' }\end{array}$ \\
\hline BTUB & $\begin{array}{l}\text { Bsh1258I } \\
\text { TaqI }\end{array}$ & $\begin{array}{l}37 \\
65\end{array}$ & $\begin{array}{l}\text { Taq } \\
\text { Taq }\end{array}$ & $\begin{array}{c}\text { 5'CGRY } \downarrow C G 3 \text { ' 3'GC } \uparrow Y R G C 5 ' \\
\text { 5'T } \downarrow \text { CGA3' 3'AGC } \uparrow \text { T 5' }\end{array}$ \\
\hline C22-8 & $\begin{array}{l}\text { Alw26I } \\
\text { MboII }\end{array}$ & $\begin{array}{l}37 \\
37\end{array}$ & $\begin{array}{l}\text { Tango } \\
\text { Tango }\end{array}$ & $\begin{array}{l}5^{\prime} \mathrm{GTCTCN}_{1} \downarrow 33^{\prime} 3^{\prime} \mathrm{CAGAGN}_{5} \uparrow 5^{\prime} \\
5^{\prime} \mathrm{GAAGAN}_{8} \downarrow 33^{\prime} 3^{\prime} \mathrm{CTTCTN}_{7} \uparrow 5^{\prime \prime}\end{array}$ \\
\hline APICO & $\begin{array}{l}\text { Afill } \\
\text { DdeI }\end{array}$ & $\begin{array}{l}37 \\
37\end{array}$ & $\begin{array}{l}\text { Tango } \\
\text { Tango }\end{array}$ & $\begin{array}{l}\text { 5'C } \downarrow \text { TTAAG3' 3'GAATT } \uparrow \text { C5' } \\
\text { 5'C } \downarrow \text { TNAG3' 3'GANT } \uparrow \text { C5' }\end{array}$ \\
\hline
\end{tabular}


site DNA in raw milk of sheep and goats of local breeds reared in Northeastern Brazil. Acta Trop 142:145-8.

de Santana Rocha D, de Sousa Moura RL, Maciel BM, Guimarães LA, O'dwyer $\mathrm{HN}$, Munhoz AD, Albuquerque GR, 2015. Detection of Toxoplasma gondii DNA in naturally infected sheep's milk. Genet Mol Res 14:8658-62.

Edvinsson B, Lappalainen M, Evengård B, the ESCMID Study Group for Toxoplasmosis, 2006. Real-time PCR targeting a 529-bp repeat element for diagnosis of toxoplasmosis. Clin Microbiol Infect 12:131-6.

EFSA 2016, Experimental studies on Toxoplasma gondii in the main livestock species (GP/EFSA/BIOHAZ/2013/01). Final report. Available from: https:/www.efsa.europa.eu/it/supporting/pub/995e

Fusco G, Rinaldi L, Guarino A, Proroga YT, Pesce A, Giuseppina de M, Cringoli G, 2007. Toxoplasma gondii in sheep from the Campania region (Italy). Vet Parasitol 149:271-4.

Hampton MM, 2015. Congenital toxoplasmosis: a review. Neonatal Netw 34:2748.

Havelaar AH, Kemmeren JM, Kortbeek LM, 2007. Disease burden of congenital toxoplasmosis. Clin Infect Dis 44:146774.

Hill DE, Dubey JP, 2013. Toxoplasma gondii prevalence in farm animals in the United States. Int J Parasitol 43:107-13.

Homan WL, Vercammen M, De Braekeleer J, Verschueren H, 2000. Identification of a 200- to 300-fold repetitive $529 \mathrm{bp}$ DNA fragment in Toxoplasma gondii, and its use for diagnostic and quantitative PCR. Int $\mathrm{J}$ for Paras 30:69-75.

Luptakova L, Benova K, Rencko A, Petrovova E, 2015. DNA detection of Toxoplasma gondii in sheep milk and blood samples in relation to phase of infection. Vet Parasitol 208:250-3.

Mancianti F, Nardoni S, D’Ascenzi C, Pedonese F, Mugnaini L, Franco F, Papini R, 2013. Seroprevalence, detection of DNA in blood and milk, and genotyping of Toxoplasma gondii in a goat population in Italy. Biomed Res Int 2013:905326.

Su C, Shwab EK, Zhou P, Zhu XQ, Dubey JP, 2010. Moving towards an integrated approach to molecular detection and identification of Toxoplasma gondii. Parasitology 137:1-11.

Vismarra A, Mangia C, Barilli E, Brindani F, Bacci C, Kramer L, 2016. Meat juice serology for Toxoplasma Gondii infection in chickens. Ital J Food Safety 5:23-6. 